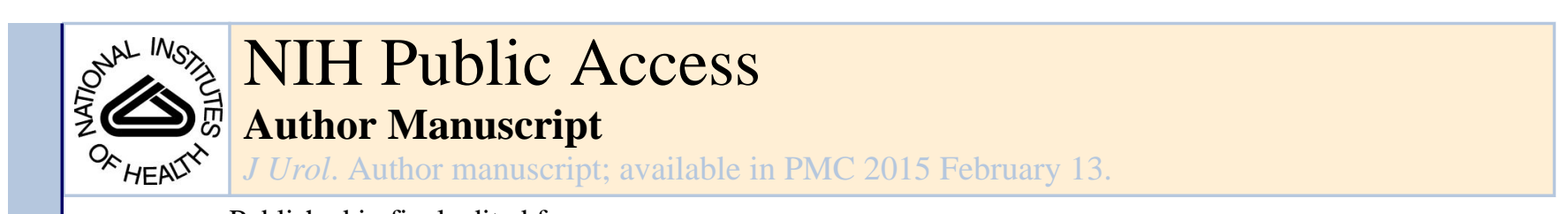

Published in final edited form as:

J Urol. 2010 November ; 184(5): 1907-1913. doi:10.1016/j.juro.2010.06.148.

\title{
Hexaminolevulinate-guided fluorescence cystoscopy reduces recurrence in patients with non-muscle invasive bladder cancer
}

\author{
Arnulf Stenzl ${ }^{1,{ }^{*}, \text { Maximilian Burger }}{ }^{2,}{ }^{*}$, Yves Fradet $^{3}$, Lance A. Mynderse ${ }^{4}$, Mark S. \\ Soloway ${ }^{5}$, J Alfred Witjes, MD $^{6}$, Martin Kriegmair, MD ${ }^{7}$, Alexander Karl ${ }^{8}$, Yu Shen ${ }^{9}$, and $\mathbf{H}$ \\ Barton Grossman, MD ${ }^{10}$
}

${ }^{1}$ Department of Urology, University Hospital, Tübingen, Germany ${ }^{2}$ Caritas St Josef Medical Center, University of Regensburg, Regensburg, Germany ${ }^{3} \mathrm{CHUQ}$ Hotel-Dieu de Quebec, Quebec, Canada ${ }^{4}$ Mayo Clinic, Rochester, MN ${ }^{5}$ University of Miami School of Medicine, Miami, FL ${ }^{6}$ Radboud University, Nijmegen Medical Centre, Nijmegen, Netherlands ${ }^{7}$ Urology Clinic, München-Planegg, Munich, Germany ${ }^{8}$ Department of Urology, Ludwig-Maximilians-University, Campus Grosshadern, Munich, Germany ${ }^{9}$ Department of Biostatistics, The University of Texas M. D. Anderson Cancer Center, Houston, TX ${ }^{10}$ Department of Urology, The University of Texas M. D. Anderson Cancer Center, Houston, TX

\section{Abstract}

(C) 2010 Published by American Urological Association Education and Research, Inc.

Corresponding author: H Barton Grossman, M.D., Department of Urology, The University of Texas MD Anderson Cancer Center, 1515 Holcombe Boulevard, Houston, TX 77030-4009, Tel: 713-792.3250, Fax: 713-794-482, hbgrossman@ @mdanderson.org.

Arnulf Stenzl and Maximilian Burger contributed equally to this manuscript.

Trial registration information

Study of improved detection and reduction of early recurrence rate in bladder cancer patients using Hexvix fluorescence cystoscopy. Number: NCT00233402

URL: http://www.clinicaltrials.gov/ct2/show/NCT00233402

Other study investigators

Richard Babayan, MD. Boston University School of Medicine, Boston, MA

Michael Cookson, MD. Vanderbilt University Medical Center, Nashville, TN

Michael Droller, MD. Mount Sinai Medical Center, New York, NY

Leonard Gomella, MD. Thomas Jefferson Medical Center, Philadelphia, PA

Maury A. Jayson, MD. South Florida Clinical Research Center, Pembroke Pines, FL

Steven Jones, MD. Cleveland Clinic Foundation, Cleveland, OH

Eduardo Kleer, MD. St Joseph Mercy Hospital, Ann Arbor, MI

Edward Messing, MD. University of Rochester Medical Center, Rochester, NY

Seth Lerner, MD. Baylor College of Medicine, Houston, TX

Gerson Lüdeke, MD. Klinik und Poliklinik für Urologie und Kinderurologie, Giessen, Germany

Alvaro Morales, MD. Kingston General Hospital, Kingston, Ontario, Canada

Unyime Nseyo, MD. VA Medical Center, Gainesville, FL

Joseph Presti, MD. Stanford Cancer Center, Palo Alto, CA

Theo de Reijke, MD. Academic Medical Center, Amsterdam, Netherlands

Chad Ritenour, MD. Emory Clinic, Atlanta, GA

Ihor Sawczuk, MD. Hackensack University Medical Center, Hackensack, NJ

Jörg Schmidbauer, MD. Academic Hospital Vienna, Austria

Publisher's Disclaimer: This is a PDF file of an unedited manuscript that has been accepted for publication. As a service to our customers we are providing this early version of the manuscript. The manuscript will undergo copyediting, typesetting, and review of the resulting proof before it is published in its final citable form. Please note that during the production process errors may be discovered which could affect the content, and all legal disclaimers that apply to the journal pertain. 
Purpose-To assess the impact that improved detection of non-muscle invasive bladder cancer with hexaminolevulinate (HAL) fluorescence cystoscopy may have on early recurrence rates.

Materials and methods-This prospective, randomized study enrolled 814 patients suspected of having bladder cancer at increased risk for recurrence. All patients underwent white light cystoscopy and mapping of lesions, followed by transurethral resection of the bladder (TURB) where indicated. Patients in the fluorescence group also received intravesical hexaminolevulinate solution at least one hour before cystoscopy to induce fluorescence of cancerous lesions, and underwent additional inspection with blue light before and after TURB. Adjuvant intravesical therapy was based on risk. Follow up cystoscopies at 3, 6 and 9 months were conducted with white light.

Results-Detection was carried out as a within-patient comparison in the fluorescence group. In this group, 286 patients were found to have at least one Ta or T1 tumor (ITT). In 47 (16\%), at least one of the tumors was seen only with fluorescence $(\mathrm{p}=0.001)$. During the 9 month follow-up period (ITT), there were tumor recurrences in 128/271 patients (47\%) in the fluorescence group and $157 / 280$ patients $(56 \%)$ in the white light group $(\mathrm{p}=0.026)$. The relative reduction in recurrence rate was $16 \%$.

Conclusions-HAL fluorescence cystoscopy significantly improves detection of Ta and T1 lesions and significantly reduces the rate of tumor recurrence at 9 months.

\section{Keywords}

bladder cancer; Hexvix; HAL; fluorescence cystoscopy; recurrence

\section{Introduction}

Cystoscopy, even when performed by experienced urologists, can miss clinically important papillary tumors and carcinoma in situ (CIS). Repeat TURB carried out only a few weeks after the initial resection demonstrates that incomplete resection is common. ${ }^{1}$ Residual tumor is found in $30 \%$ to $44 \%$ of patients resected up to 8 weeks after the original surgery, ${ }^{2-4}$ and the rate can be as high as $70 \%$ for high-grade tumors. ${ }^{5,6}$

Fluorescence cystoscopy uses photoactive compounds to enhance the visual demarcation between normal and neoplastic tissue. Endogenous aminolevulinic acid (ALA) is a natural precursor of the photoactive intermediate, protoporphyrin IX (PpIX). Intravesical hexaminolevulinic acid, a hexyl ester of 5-ALA, induces accumulation of PpIX in malignant cells, which fluoresce when exposed to light between $375 \mathrm{~nm}$ and $440 \mathrm{~nm}, 7,8$ enabling the detection of more exophytic tumors and CIS than white light cystoscopy. ${ }^{9-13}$

The objective of this international study was to assess the impact that improved detection of bladder cancer with hexaminolevulinate cystoscopy has on tumor recurrence. 


\section{Methods}

\section{Patients}

Twenty-eight centers (19 USA and Canada; 9 Europe) enrolled patients with suspected Ta and/or T1 bladder cancer on the basis of outpatient cystoscopy. Eligible patients were at increased risk for recurrence based on the presence of more than one initial or recurrent papillary bladder tumor or a recurrence within 12 months of a previous bladder cancer. Patients with gross hematuria, porphyria, and those who received Bacillus Calmette-Guerin (BCG) or multiple instillation chemotherapy in the three months prior to initial TURB were excluded.

The trial was conducted in accordance with the International Conference on Harmonization (ICH) guidelines for Good Clinical Practice (GCP) and the Declaration of Helsinki (10 September 2004 version). All patients provided written informed consent

\section{Hexaminolevulinate treatment}

Hexaminolevulinate (HAL, Photocure, Norway) was supplied as $85 \mathrm{mg}$ powder for reconstitution in $50 \mathrm{~mL}$ of phosphate buffered saline. The solution was instilled into the bladder and was to be retained for one hour. A xenon light source (D-light C system ${ }^{\circledR}$ (Karl Storz Co, Tüttlingen, Germany)) was used for blue and white light cystoscopy.

\section{Randomization and treatment protocol}

Randomization was carried out centrally and was stratified for patients presenting with initial and recurrent bladder cancer. Patients in the white light group underwent cystoscopy and mapping of bladder lesions followed by TURB with white light (Figure 1).

In the fluorescence cystoscopy group, lesions were first mapped using white light cystoscopy. Immediately after mapping, a second randomization was performed to ensure that a thorough inspection was carried out with white light. Patients randomized to discontinue were excluded from further efficacy analyses but were monitored for adverse events. Patients randomized to continue in the study had their bladder mapped again using blue light. They then had TURB using blue light to evaluate the completeness of the resection (Figure 1).

At centers with no prior experience with fluorescence cystoscopy, the first five patients enrolled were training patients. They were not randomized into the study and received fluorescence cystoscopy and were only included in the safety analysis.

For all patients continuing in the study, all exophytic lesions were resected and all suspicious lesions were biopsied. These biopsies were analyzed both by a local pathologist and by a panel of central pathologists blinded to the decision of the local pathologist. The central pathology panel consensus read was used as the Standard of Truth for the detection endpoints. For the recurrence endpoint, local pathology was used because all clinical decisions were based on local pathology. 
Flat lesions were graded according to the World Health Organization (WHO)/International Society of Urological Pathology (ISUP) 1998 consensus classification of urothelial (transitional cell) neoplasms of the urinary bladder ${ }^{14}$ and according to McKenney et al, ${ }^{15}$ while papillary lesions were graded according to WHO $1973 .{ }^{16}$

Patients found to have high grade bladder cancer, T1, or carcinoma in situ according to the local pathological examination were to receive intravesical BCG unless contraindicated. Other intravesical therapy was not permitted.

Only those patients found to have histologically-confirmed Ta or T1 tumors, based on the diagnosis of the local pathologist, entered the follow-up phase of the study.

Cystoscopy with white light was performed at 3, 6 and 9 months following initial resection or until recurrence. Recurrence was to be confirmed histologically.

\section{Analyses and Statistical methods}

The study assessed the effects of fluorescence cystoscopy on detection of non-muscle invasive bladder tumors and on bladder cancer recurrence. The analysis populations are shown in Table 1. The primary detection endpoint was the proportion of patients with histologically-confirmed Ta or T1 tumors in the fluorescence cystoscopy group who had at least one additional histologically-confirmed Ta or T1 tumor detected with blue but not white light.

Secondary endpoints included the proportion of patients in the fluorescence cystoscopy group who had additional CIS lesions detected with blue light. For analysis of the detection endpoints, an exact test for single proportion, using the cumulative binomial distribution with a hypothesized additional detection in $10 \%$ of the patients (2-sided) was used.

False positive detection rates were derived as the number of false positive lesions (i.e. suspected but with negative histology) detected with blue or white light divided by the total number of lesions suspected with blue or white light, respectively. In this analysis, the finding of dysplasia, carcinoma in situ, or T1-4 bladder cancer were considered positive.

The primary recurrence endpoint was a comparison of the proportion of patients in each group who had a histologically-confirmed Ta or T1 tumor at baseline, and who were subsequently diagnosed with recurrent tumors (CIS, Ta, T1-4) within 9 months. Patients with invasive disease, with CIS only or with negative pathology were not followed for recurrence. Patients who did not complete the 9 months surveillance and those who had visual assessment of a lesion without biopsy were imputed to have a recurrence (ITT Recurrence). For those that did not complete the scheduled surveillance, the recurrence was deemed to have taken place at the time point following the last tumor-free diagnosis.

The Cochran-Mantel-Haenszel (CMH) Chi-square test with center as stratification factor (2sided) was used. Other efficacy and safety variables were summarized using descriptive statistics. 


\section{Results \\ Detection}

Detection was assessed as a within-patient comparison in the fluorescence cystoscopy group only. Of the 365 patients in the ITT population in the fluorescence group, $286 \mathrm{had}$ Ta and/or T1 tumors, whereas 79 had either no tumor, muscle invasive tumors or CIS only (Table 1). The mean and median retention times for HAL were $90( \pm 38)$ and 80 minutes, respectively. Of the 286 patients in the fluorescence group with Ta or T1 tumors according to central pathology assessment (ITT Detection), 47 had additional Ta or T1 tumors that were visible only with fluorescence $(16 \%, \mathrm{p}=0.001$, Table 2$)$. In these 47 patients, the worst stage and grade of tumor found with blue light was TaG2 in 27 (57\%); T1G2 in 1 (2\%); TaG3 in 12, $26 \%$ ) and T1G3 in 7 (15\%). Results in the PPS were similar with $17 \%$ of patients having at least one Ta or $\mathrm{T} 1$ detected with fluorescence only $(\mathrm{p}=0.0005)$.

Of the 41 patients who had CIS, 19 (46\%) had at least one CIS lesion that was detected only with blue light, and 13 (32\%) of these patients did not have any CIS detected by white light ( $\mathrm{p}<0.0001$ ). Seven of the 13 patients presented with co-existing Ta tumors.

Of the 988 lesions found in patients in the fluorescence cystoscopy group, false positive was recorded in 120 fluorescence-guided biopsies (12\%). White light-guided biopsies were taken in both the fluorescence group (before blue light inspection) and the white light group. The false positive results for white light were $97 / 917(11 \%)$ in the fluorescence group and 91/933 (10\%) in the white light group. There was no significant difference in the rates of false positive results between white light and fluorescence cystoscopy.

\section{Recurrence}

The recurrence endpoint was assessed by comparing the recurrence rates in patients with Ta or T1 in both treatment groups. The ITT groups for the recurrence endpoint comprised 271 in the fluorescence cystoscopy group and 280 in the white light group (Figure 2).

The groups were similar in age, sex, race, bladder cancer history, and prior intravesical therapy (Table 3). The mean duration since the first diagnosis of bladder cancer was 4.6 years. The proportion of patients with initial tumors was similar in both groups as was the highest stage and grade at study entry. BCG was administered to $55(20 \%)$ patients of the white light group and to $50(19 \%)$ of the patients in the fluoresence group.

During the 9-months surveillance period, 128/271 patients (47\%) in the fluorescence group and $157 / 280$ patients (56\%) in the white light group had either a pathologically confirmed tumor recurrence or incomplete data that was imputed as a recurrence (ITT Recurrence, $\mathrm{p}=0.026$ ). In the fluorescence and white light groups, 45 and 55 patients respectively, were imputed to have a recurrence. (eight and 10 respectively due lack of histological confirmation and the remainder due to lack of 9-month follow-up). The relative reduction in recurrence rate in the fluorescence group was 16\%. At each time point (3, 6 and 9 months) the number of recurrences was lower in the HAL group compared to the white light group (Figure 3). 
Seventy-one patients (26\%) in the fluorescence group and 78 (28\%) in the white light group did not complete the study according to the protocol and were excluded from the PPS analysis. The PPS results were similar to those for the ITT group: 72/200 (36\%) patients in the fluorescence group and 92/202 (46\%) in the white light group had a recurrence within the 9-month study period (PPS, $\mathrm{p}=0.029$ ). The relative reduction in recurrence rate was $22 \%$.

Patients with a history of recurrent bladder cancer experienced a higher rate of tumor recurrence than those with initial cancer (Table 4). Fluorescence cystoscopy resulted in a significant reduction in recurrence for those with recurrent cancer (PPS p=0.04). Patients with TaG1 or TaG2 tumors at baseline randomized to fluorescence were less likely to experience a recurrence (PPS $\mathrm{p}=0.02)$.

Of the patients with documented recurrent tumors during the 9-month follow-up period $13 / 83(16 \%)$ patients in the fluorescence group and 24/101 (24\%) in the white light group experienced recurrence of worrisome cancers, such as CIS or recurrence of T1 or muscleinvasive disease ( $\mathrm{p}=0.17$ ). Progression to muscle invasion occurred in 7 patients in the white light group and 5 in the fluorescence group.

\section{Safety}

A similar level of adverse events (AEs) was experienced by both groups (Table 5). Most were mild to moderate in intensity and were expected with bladder tumor resection. No phototoxicity was reported.

The most common serious adverse events (SAEs) in both groups were hematuria and urinary retention. Only one SAE was thought to be possibly related to hexaminolevulinate (bladder spasm, which resulted in prolonged hospitalization). Five deaths were reported in each study group but were not related to the study procedures.

\section{Discussion}

This international study demonstrated that HAL fluorescence cystoscopy significantly improved the detection of Ta and T1 tumors in $16 \%$ (47) of patients ( $\mathrm{p}=0.001$, ITT Detection). The number of false positive findings was low and was similar in both groups (fluorescence 12\%; white light (in fluorescence group) 11\%; white light group 10\%) suggesting that the increased rate of detection in the fluorescence group was not simply a result of taking more biopsies.

These results are in line with previous studies that have shown improved detection of lesions with HAL fluorescence cystoscopy. ${ }^{9,11-13,17}$ In this study, many of the additional tumors detected through blue light inspection were clinically significant and included grade 2 and 3 tumors and $\mathrm{T} 1$ tumors that had been overlooked during white light inspection. Furthermore, fluorescence cystoscopy revealed CIS in 32\% (13/41) of patients whose condition went undetected with white light. Among seven patients with Ta disease, co-existing CIS was detected only with fluorescence cystoscopy.

Improved detection of tumors would be expected to benefit the patient through better disease staging, which can result in more appropriate management, and through more complete 
tumor mapping, which would result in a more complete resection. The tumor recurrence rate provides an objective measure of these expected benefits and our results demonstrated significantly lower recurrence rates among patients who underwent fluorescence cystoscopy.

According to the ITT analysis, the relative reduction in cancer recurrence with fluorescence cystoscopy at 9 months was $16 \%$ ( $\mathrm{p}=0.026$ ), and was $21 \%$ for the PPS. Recurrence of worrisome disease (CIS, T1, or muscle invasive bladder cancer) occurred in $16 \%$ of patients in the fluorescence group and $24 \%$ in the white light group $(\mathrm{p}=0.17)$.

The absolute decrease in tumor recurrence at 9 months was $9 \%$ in the ITT analysis, suggesting that only 11 patients need to be treated in order to avoid one recurrence. This compares favorably with other treatments, ${ }^{18}$ particularly since HAL fluorescence cystoscopy requires only one instillation of hexaminolevulinic acid and is associated with minimal toxicity.

Our findings are similar to those of several small randomized studies that reported improved rates of recurrence with fluorescence cystoscopy using $\mathrm{ALA}^{2,3,19}$ and HAL. ${ }^{20}$ However, a recent multi-institutional study of ALA reported that while fluorescence detected more bladder cancers, there was no difference in the rate of tumor recurrence. ${ }^{21}$ ALA requires a much longer retention time than HAL. The median instillation time with ALA in this study was only 2.1 hours, and the participating urologists had limited experience with fluorescence. These factors may have resulted in the failure to demonstrate a significant difference in time to recurrence.

This study focused on patients with Ta and/or T1 bladder cancer at increased risk for recurrence who had not received BCG or multidose intravesical chemotherapy within 3 months. Therefore, the applicability of these findings to patients with other types of bladder cancer is uncertain. An additional limitation is that subset analyses of the recurrence rates by type of cancer were not pre-specified and adequately powered and should only be considered hypothesis generating.

Bladder cancer is the most expensive cancer to treat per patient, with the lifetime cost per patient estimated at up to $\$ 200,000 .{ }^{22}$ Approximately $75 \%$ of the post-diagnosis costs relate to pre- and intra-operative management, post-surgical complications, and frequent diagnostic testing. ${ }^{23}$ While fluorescence diagnosis incurs initial expense, analyses suggest that this can be offset by improved disease-free survival. ${ }^{24,} 25$ Zaak et al demonstrated that by using fluorescence cystoscopy in 115 patients, at least 20 TURBs could be avoided over a 5-year period. ${ }^{26}$ Malmstrom et al concluded that if fluorescence cystoscopy were used only in high-risk patients it could save $\$ 655,000$ in the first year alone, with significant savings if it were used for all TURBs in high and medium-risk patients. ${ }^{27}$ Actual cost savings will, of course, be affected by local treatment and monitoring protocols.

\section{Conclusion}

Hexaminolevulinate-induced fluorescence cystoscopy significantly improves detection of bladder cancer leading to a more complete resection and significantly better disease-free survival. This novel change in endoscopic imaging is safe and easily learned. 


\section{Acknowledgments}

The study was funded by Photocure ASA (Oslo, Norway).

\section{Abbreviations}

$\begin{array}{ll}\text { ALA } & \text { aminolevulinic acid } \\ \text { CIS } & \text { Carcinoma in situ } \\ \text { HAL } & \text { hexaminolevulinate } \\ \text { ITT } & \text { intent to treat } \\ \text { PPS } & \text { per protocol set } \\ \text { TURB } & \text { transurethral resection of the bladder }\end{array}$

\section{References}

1. Jakse G, Algaba F, Malmström PU, et al. A second-look TUR in T1 transitional cell carcinoma: why? Eur Urol. 2004; 45:539. [PubMed: 15082193]

2. Babjuk M, Soukup V, Petrik R, et al. 5-aminolaevulinic acid-induced fluorescence cystoscopy during transurethral resection reduces the risk of recurrence in stage $\mathrm{Ta} / \mathrm{T} 1$ bladder cancer. BJU Int. 2005; 96:798. [PubMed: 16153204]

3. Daniltchenko D, Riedl CR, Sachs MD, et al. Long-term benefit of 5-aminolevulinic acid fluorescence assisted transurethral resection of superficial bladder cancer: 5 -year results of a prospective randomized study. J Urol. 2005; 174:2129. [PubMed: 16280742]

4. Klaen R, Loy V, Huland H. Residual tumor discovered in routine second transurethral resection in patients with stage T1 transitional cell carcinoma of the bladder. J Urol. 1991; 146:316. [PubMed: 1856924]

5. Al'-Shukri, SKh; Daniltchenko, DI.; Kënig, F., et al. ALA fluorescent diagnosis of bladder cancer. Urologia. 2000; 5:48.

6. Köhrmann KU, Woeste M, Kappes J, et al. The value of secondary transurethral resection for superficial bladder tumors. Akt Urol. 1994; 25:208.

7. Krieg RC, Messmann H, Rauch J, et al. Metabolic characterization of tumor cell-specific protoporphyrin IX accumulation after exposure to 5-aminolevulinic acid in human colonic cells. $\mathrm{J}$ Photochem Photobiol B. 2002; 76:518.

8. Kennedy J-C, Pottier RH, Pross DC. Photodynamic therapy with endogenous protoporphyrin IX: basic principles and present clinical experience. J Photochem Photobiol B. 1990; 6:143. [PubMed: 2121931]

9. Jichlinski P, Guillou L, Karlsen S, et al. Hexyl aminolevulinate fluorescence cystoscopy: a new diagnostic tool for photodiagnosis of superficial bladder cancer - a multicenter study. J Urol. 2003; 170:226. [PubMed: 12796694]

10. Jocham D, Witjes F, Wagner S, et al. Improved detection and treatment of bladder cancer using hexaminolevulinate imaging: a prospective, phase III multicenter study. J Urol. 2005; 174:862. [PubMed: 16093971]

11. Fradet Y, Grossman HB, Gomella L, et al. A comparison of hexaminolevulinate fluorescence cystoscopy and white light cystoscopy for the detection of carcinoma in situ in patients with bladder cancer: a phase III, multicenter study. J Urol. 2007; 178:68. [PubMed: 17499291]

12. Grossman HB, Gomella L, Fradet Y, et al. A phase III, multicenter comparison of hexaminolevulinate fluorescence cystoscopy and white light cystoscopy for the detection of superficial papillary lesions in patients with bladder cancer. J Urol. 2007; 178:62. [PubMed: 17499283] 
13. Schmidbauer J, Witjes F, Schneller M, et al. Improved detection of urothelial carcinoma in situ with hexaminolevulinate fluorescence cystoscopy. J Urol. 2004; 171:135. [PubMed: 14665861]

14. Epstein JI, Amin MB, Reuter MD, et al. The World Health Organisation/International Society of Urological Pathology consensus classification of urothelial (transitional cell) neoplasms of the urinary bladder. Am J Surg Pathol. 1998; 22:1435. [PubMed: 9850170]

15. McKenney JK, Gomez JA, Desai S, et al. Morphologic expressions of urothelial carcinoma in situ. A detailed evaluation of its histologic patterns with emphasis on carcinoma in situ with microinvasion. Am J Surg Pathol. 2001; 25:356. [PubMed: 11224606]

16. Mostofio, FK.; Sobin, LH.; Torloni, H. International Histological Classification of Tumours. World Health Organisation; Geneva: 1973. Histopathological typing of urinary bladder tumours.

17. Jichlinski P, Forrer M, Mizeret J, et al. Clinical evaluation of a method for detecting superficial transitional cell carcinoma of the bladder by light-induced fluorescence of protoporphyrin IX following topical application of 5-aminolevulinic acid: preliminary results. Lasers Surg med. 1997; 20:402. [PubMed: 9142679]

18. Schroder FH, Hugosson J, Roobol MJ, et al. Screening and prostate-cancer mortality in a randomized European study. New Engl J Med. 2009; 360:1320. [PubMed: 19297566]

19. Denzinger S, Burger M, Walter B, et al. Clinically relevant reduction in risk of recurrence of superficial bladder cancer using 5-aminolevulinic acid induced fluorescence diagnosis: 8-year results of prospective randomized study. Urology. 2007; 69:675. [PubMed: 17445650]

20. Geavlete B, Multescu R, Georgescu D, et al. Hexaminolevulinate fluorescence cystoscopy and transurethral resection of the bladder in noninvasive bladder tumors. J Endourol. 2009; 23:977. [PubMed: 19473068]

21. Schumacher, MC.; Holmang, S.; Davidsson, T., et al. Transurethral resection of non-muscleinvasive bladder transitional cell cancers with or without 5-ALA under visible and fluorescent light - multicenter phase III clinical trial, in the 24th annual meeting of the European Association of Urology; 2009; Stockholm, Sweden.

22. Botteman MF, Pashos CL, Redaelli A, et al. The health economics of bladder cancer: a comprehensive review of the published literature. Pharmacoeconomics. 2003; 21:1314.

23. Marchetti A, Wang L, Magar R, et al. Management of patients with Bacilli Calmette-Guerinrefractory carcinoma in situ of the urinary bladder: cost implications of a clinical trial for valrubicin. Clin Ther. 2000; 22:422. [PubMed: 10823364]

24. Burger M, Zaak D, Stief CG, et al. Photodynamic diagnostics and noninvasive bladder cancer: is it cost-effective in long-term application? A Germany-based cost analysis. Eur Urol. 2007; 52:142. [PubMed: 17267099]

25. Sievert KD, Amend B, Nagele U, et al. Economic aspects of bladder cancer: what are the benefits and costs? World J Urol. 2009; 27:295. [PubMed: 19271220]

26. Zaak D, Wieland WF, Stief CG, et al. Routine use of photodynamic diagnosis of bladder cancer. Pract Econ Issues Eur Urol. 2008; (Supplement 7):S536.

27. Malmstrom PU, Hedelin H. Potential cost savings through the use of fluorescence cystoscopy in superficial bladder cancer: development of an economic model. Urology. 2006; 68:S40. 
Inclusion

Time 0

Time 3 months

Time 6 months

Time 9 months

\section{Randomization and stratification}
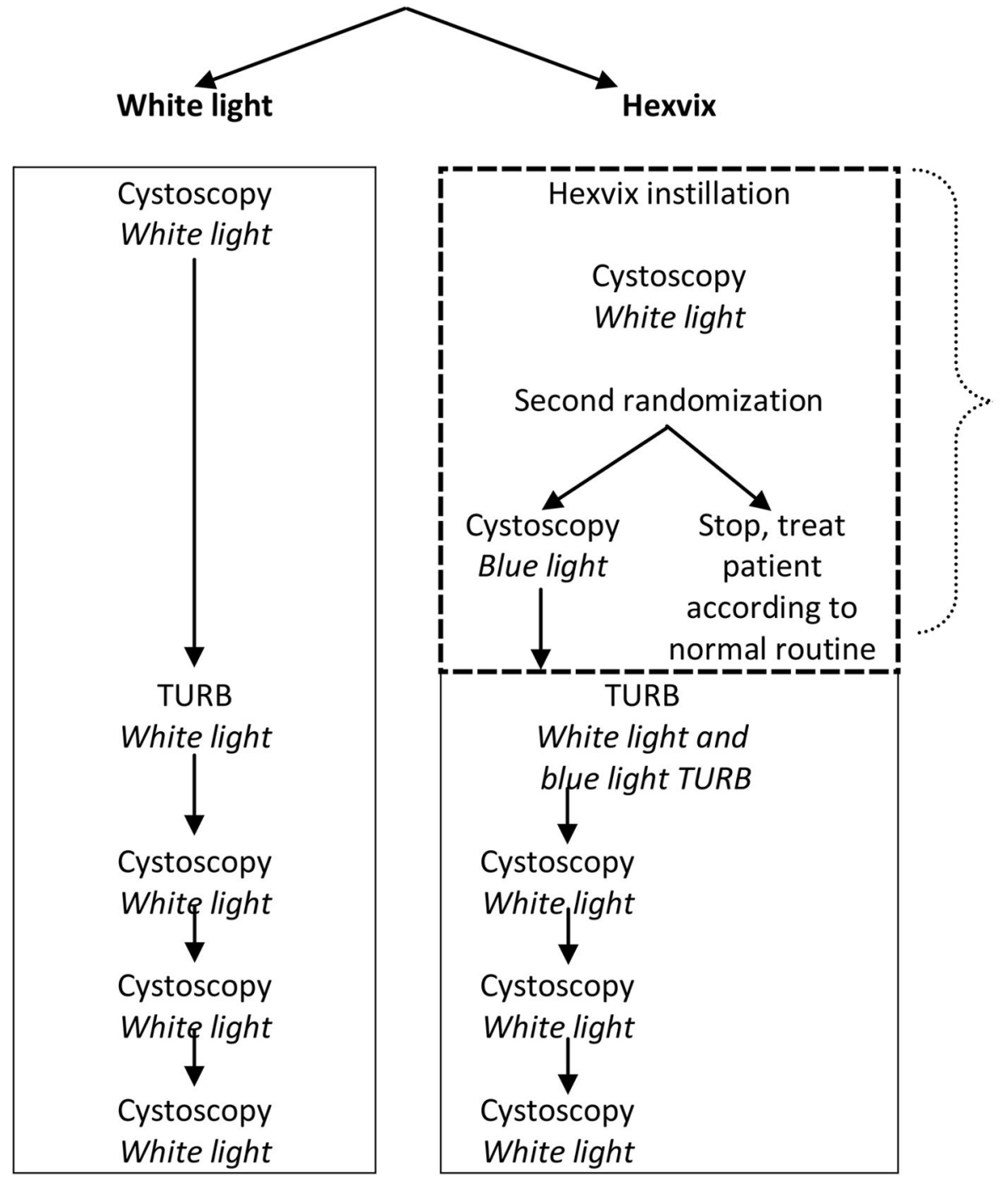

Figure 1.

Study flow 


\section{Analysis Population Recurrence Endpoint}

Exclusion from ITT,

$(\mathrm{N}=111)$

- No study drug (4)

- No cystoscopy (2)

- No BL cystoscopy (2)

- No pathology (9)

- No Ta/Ti (94)

\section{HAL Group}

$\mathrm{N}=382^{*}$

Subjects

randomized
Exclusion from PPS, $(\mathrm{N}=71)$

- Not eligible (1)

- Equipment failure (4)

- No follow up data (21)

- CT withing 24 hours (7)

- BCG outside protocol (12)

- Hexvix instillation to TURB $<45$ min (2)

- Hexvix Instillation < 15min (2)

- Incomplete follow up (22)

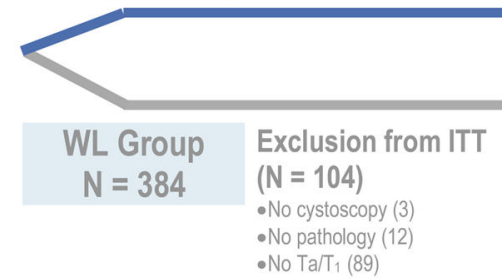

\section{randomized}

$$
\begin{aligned}
& \text { WL Group Exclusion from ITT } \\
& \text { - No cystoscopy (3) } \\
& \text { - No Ta/T1 (89) }
\end{aligned}
$$

*Excluding patients randomized to no blue light (BL)

Figure 2.

Analysis populations, recurrence endpoint 


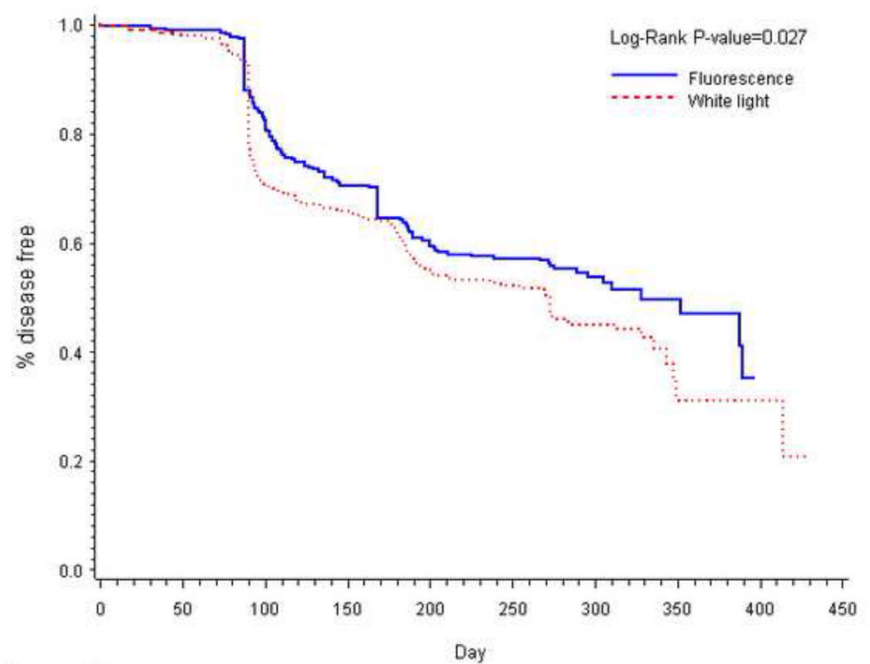

Number of Subjects at Risk

$\begin{array}{clllllllll}\text { White light } & 280 & 275 & 198 & 185 & 155 & 145 & 59 & 10 & 4 \\ \text { Fluorescence } & 271 & 269 & 225 & 192 & 165 & 154 & 63 & 20 & 5\end{array}$

Figure 3.

Kaplan-Meier plot of time to recurrence by treatment (ITT). 


\section{Table 1}

Analysis populations

\begin{tabular}{|c|c|c|c|}
\hline \multirow[b]{2}{*}{ Population } & & \multirow[t]{2}{*}{ Hexvix group } & \multirow{2}{*}{$\begin{array}{l}\text { White light group } \\
\text { number of patients }\end{array}$} \\
\hline & & & \\
\hline Safety Set & $\begin{array}{l}\text { All patients receiving HAL, and with safety data, includes } \\
\text { training patients in the fluorescence cystoscopy group re- } \\
\text { randomized out of the study. }\end{array}$ & 421 & 381 \\
\hline All patients randomized & $\begin{array}{l}\text { Excludes patients re-randomized out of the fluorescence } \\
\text { cystoscopy group. }\end{array}$ & 395 & 384 \\
\hline $\begin{array}{l}\text { ITT Set for detection primary } \\
\text { endpoint analysis }\end{array}$ & $\begin{array}{l}\text { Patients receiving HAL, inspected with white and blue } \\
\text { light, with histologically-confirmed results by central } \\
\text { pathology consensus diagnosis. }\end{array}$ & $365^{2}$ & $\mathrm{n} / \mathrm{a}^{l}$ \\
\hline PPS for detection primary endpoint & $\begin{array}{l}\text { Same as ITT set but excluding protocol violations such as } \\
\text { HAL retention time or equipment failure. }\end{array}$ & 352 & $\mathrm{n} / \mathrm{a}^{l}$ \\
\hline $\begin{array}{l}\text { ITT Subset for recurrence primary } \\
\text { endpoint analysis }\end{array}$ & $\begin{array}{l}\text { Patients receiving HAL, inspected with white and blue } \\
\text { light, with histologically-confirmed Ta or T1 tumors } \\
\text { (local pathology read) at baseline. }\end{array}$ & 271 & 280 \\
\hline $\begin{array}{l}\text { PPS Subset for recurrence primary } \\
\text { endpoint }\end{array}$ & $\begin{array}{l}\text { Same as ITT set but excluding patients who did not } \\
\text { complete the study according to the protocol. }\end{array}$ & 200 & 202 \\
\hline \multicolumn{4}{|c|}{${ }^{1}$ Not applicable, False positive analysis only } \\
\hline \multicolumn{4}{|l|}{${ }^{2}$ Exclusion from ITT for detection: } \\
\hline \multicolumn{4}{|c|}{13 patients re- randomization out of fluorescence group } \\
\hline \multicolumn{4}{|l|}{4 withdrawn before treatment } \\
\hline \multicolumn{4}{|l|}{2 no cystoscopy } \\
\hline 2 no blue light inspection & & & \\
\hline
\end{tabular}




\section{Table 2}

\section{Detection endpoints}

HAL fluorescence group, $n=365$ (ITT Detection)

\begin{tabular}{lcc}
\hline & $\begin{array}{c}\text { Total, n (\% of patients in the ITT Detection } \\
\text { group with stated tumor type) }\end{array}$ & $\begin{array}{c}\text { Patients with at least one lesion of each type detected } \\
\text { only with fluorescence }\end{array}$ \\
\hline Patients with Ta or T1 tumors & $286(78.4 \%)$ & $47(16.4 \%)$ \\
& $262(71.8 \%)$ & $(95 \%$ CI: $12.3-21.2) \%$ \\
Patients with Ta tumors & $63(17.3 \%)$ & $81(15.6 \%)$ \\
Patients with T1 tumors & $41(11.2 \%)$ & $8(12.7 \%)$ \\
Patients with CIS & $19(46.3 \%)$ \\
\hline
\end{tabular}

Note: patients may have more than one tumor type 
Table 3

Baseline characteristics (ITT Recurrence group)

\begin{tabular}{|c|c|c|}
\hline & $\begin{array}{l}\text { Fluorescence group } \\
\qquad \mathrm{N}=\mathbf{2 7 1}\end{array}$ & $\begin{array}{l}\text { White light group } \\
\quad \mathbf{N}=\mathbf{2 8 0}\end{array}$ \\
\hline Sex, male : female (\%) & $212: 59(78.2 \%: 21.8 \%)$ & $223: 57(79.3 \%: 20.4 \%)$ \\
\hline \multicolumn{3}{|l|}{ Ethnic group, n (\%) } \\
\hline White & $250(92.3 \%)$ & $270(96.4 \%)$ \\
\hline Black & $4(1.5 \%)$ & $3(1.1 \%)$ \\
\hline Hispanic & $4(1.5 \%)$ & $2(0.7 \%)$ \\
\hline Asian & $2(0.7 \%)$ & - \\
\hline Other & $11(4.1 \%)$ & $5(1.8 \%)$ \\
\hline Mean (SD) age, years & $68.0(10.8)$ & $69.6(10.7)$ \\
\hline Mean (SD) height, $\mathrm{cm}$ & $172(8.9)$ & $173(9.6)$ \\
\hline Mean (SD) weight, $\mathrm{kg}$ & $82.0(16.0)$ & $83.5(18.1)$ \\
\hline \multicolumn{3}{|l|}{ Bladder cancer history, $\mathrm{n}(\%)$} \\
\hline Initial & $101(37.3 \%)$ & $123(43.9 \%)$ \\
\hline Recurrent & $170(62.7 \%)$ & $157(56.1 \%)$ \\
\hline Mean years (SD) with Bladder cancer & $4.4(4.9)$ & $5.0(5.8)$ \\
\hline Prior intravesical chemotherapy & $51(19.4 \%)$ & $55(20.4 \%)$ \\
\hline Mean years (SD) received chemotherapy & $2.2(4.9)$ & $1.9(2.2)$ \\
\hline Prior intravesical $\mathrm{BCG}, \mathrm{n}(\%)$ & $53(20.2 \%)$ & $65(24.3 \%)$ \\
\hline Years received BCG, mean (SD) & $2.9(3.1)$ & $3.9(4.4)$ \\
\hline
\end{tabular}


Table 4

Recurrence rates in groups stratified by risk

\begin{tabular}{|c|c|c|c|c|}
\hline & $\mathbf{N}$ & Recurrence, fluorescence group & $\begin{array}{c}\text { Recurrence, white light } \\
\text { group }\end{array}$ & P value \\
\hline Patients with initial cancer at baseline & 224 & $42 / 101(41.6 \%)$ & $60 / 123(48.8 \%)$ & 0.31 \\
\hline Patients with recurrent cancer at baseline & 327 & $86 / 170(50.6 \%)$ & $97 / 157(61.8 \%)$ & 0.04 \\
\hline Patients with TaG1 or $\mathrm{TaG} 2$ at baseline & 422 & $99 / 218(45.4 \%)$ & $113 / 204(55.4 \%)$ & 0.02 \\
\hline $\begin{array}{l}\text { Patients with TaG3, Ta and CIS, T1, T1 and CIS at } \\
\text { baseline }\end{array}$ & 156 & $40 / 73(54.8 \%)$ & $47 / 83(56.6 \%)$ & 0.48 \\
\hline
\end{tabular}


Table 5

Adverse events

\begin{tabular}{lcc}
\hline & Fluorescence group, n=365 & White light group, n=361 \\
\hline Patients experiencing AEs, $\mathrm{n}(\%)$ & $202(48.0 \%)$ & $193(50.7 \%)$ \\
Total AEs, $\mathrm{n}$ & 562 & 476 \\
Mild to moderate, $\mathrm{n}$ & 525 & 455 \\
\hline Most common AEs & & \\
Renal and urinary disorders & $31.4 \%$ & $32.0 \%$ \\
& all patients/treatment-related & \\
- Haematuria & $63(15 \%) / 11(2.6 \%)$ & $64(16.8 \%)$ \\
- Dysuria & $40(9.5 \%) / 5(1.2 \%)$ & $28(7.3 \%)$ \\
- Bladder spasm & $20(4.8 \%) / 4(1.0 \%)$ & $18(4.7 \%)$ \\
- Urinary retention & $19(4.5 \%) / 4(1.0 \%)$ & $14(3.7 \%)$ \\
- Bladder pain & $17(4.0 \%) / 4(1.0 \%)$ & $13(3.4 \%)$ \\
\hline Serious AEs, & 51 & 39 \\
Patients, n (\%) & $39(9.3 \%)$ & $32(8.4 \%)$ \\
\hline
\end{tabular}

